\title{
Erratum to: Alzheimer disease and cancer risk: a meta-analysis
}

\author{
Hai-bin Shi • Bo Tang $\cdot$ Yao-Wen Liu • \\ Xue-Feng Wang · Guo-Jun Chen
}

Published online: 28 August 2014

(C) Springer-Verlag Berlin Heidelberg 2014

\section{Erratum to: J Cancer Res Clin Oncol}

\section{DOI 10.1007/s00432-014-1773-5}

Unfortunately, the initial sentence in the "Identification and eligibility of relevant studies" section of the Methods was incorrectly published. The correct statement should read:

Electronic databases including PubMed (from 1950 to Nov 2013), EMBASE (from 1947 to Nov 2013), and Web of Science (from 1900 to Nov 2013) were searched.

The online version of the original article can be found under doi:10.1007/s00432-014-1773-5.

H. Shi $\cdot$ B. Tang $\cdot$ Y.-W. Liu $\cdot$ X.-F. Wang $\cdot$ G.-J. Chen $(\bowtie)$

Department of Neurology, Chongqing Key Laboratory of Neurology, The First Affiliated Hospital of Chongqing

Medical University, 1 Youyi Road, Yuzhong District, Chongqing

400016, China

e-mail: woodchen2015@163.com 